\title{
Relationship between internal defect size and fatigue limit in selective laser melted Inconel 718
}

\author{
Manatsu OGAWAHARA* and Shinya SASAKI** \\ *Department of Mechanical Engineering, Graduate School of Tokyo University of Science \\ 6-3-1 Niijuku Katsushika-ku, Tokyo, 125-8585, Japan \\ E-mail: 4519507@ed.tus.ac.jp \\ **Department of Mechanical Engineering, Tokyo University of Science \\ 6-3-1 Niijuku Katsushika-ku, Tokyo, 125-8585, Japan
}

Received: 27 July 2020; Revised: 15 October 2020; Accepted: 4 November 2020

\begin{abstract}
Inconel 718 is a Ni-based superalloy, which shows excellent mechanical properties such as tensile strength, fatigue strength, and creep strength at high temperatures up to $700{ }^{\circ} \mathrm{C}$. However, as Inconel 718 is a difficult-to-cut material, it causes severe wear of machining tools. Fabricating Inconel 718 by Selective laser melting (SLM), a type of additive manufacturing (AM), is therefore expected as the manufacturing method to deal with this problem. However, it is impossible to completely prevent the occurrence of the internal defects in SLM parts. These internal defects deteriorate the mechanical properties such as the fatigue strength of SLM parts. Though the effect of the internal defect size on the fatigue limit of SLM alloys such as Ti6Al4V and AlSi10Mg has been extensively investigated, its effect on SLM Inconel 718 has not yet been investigated. In this study, Inconel 718 specimens with various internal defect sizes were fabricated by SLM and the effect of the internal defect size on their fatigue strength was investigated. Internal defect size distribution in as built specimen can be approximated by Gumbel distribution. The specimens containing internal defects with a diameter of about $400 \mu \mathrm{m}$ showed no significant decrease in the fatigue strength. In the case of the plane specimen, the fatigue limit predicted using the statistic of extremes and the $\sqrt{\text { area }}$ parameter model was $40 \%$ higher than that obtained experimentally.
\end{abstract}

Keywords : Additive manufacturing(AM), Selective laser melting(SLM), Inconel 718, Fatigue, Internal defect

\section{Introduction}

With the rapid growth of modern industries, additive manufacturing (AM) has emerged as an efficient approach for processing alloys. This technique produces light parts using complicated structures and topology optimization. It has also enabled the replacement of multiple machine parts by a single part. In addition, unlike conventional processing methods, AM allows a wide variety of parts to be produced in small quantities. Selective laser melting (SLM) works on the principle of powder bed fusion and shows the highest repeatability among metal AM processing methods. SLM involves the use of one or more lasers to selectively melt the powder layers with thicknesses of several tens of $\mu \mathrm{m}$ each.

Aerospace parts are made up of lightweight alloys which are obtained in low yields and require long processing times. Aerospace parts are mainly fabricated using aluminum, nickel, and titanium alloys (Zhang et al., 2018) (Arunachalam et al., 2004). Inconel 718 is the most widely used Ni-based alloy owing to its excellent high-temperature (above $700{ }^{\circ} \mathrm{C}$ ) mechanical properties and corrosion resistance (Akca and Gursel, 2015) (Sharman et al., 2001). However, though casting, forging, and powder metallurgy have been used to process Inconel 718 (Akca and Gursel, 2015), it is difficult to cut and requires extensive processing with tools, which must be replaced frequently (Arunachalam et al., 2004) (Sharman et al., 2001).

Although SLM is widely used for fabricating machine parts, it inevitably generates internal defects and induces anisotropy in the fabricated parts (Sridharan et al., 2016) (Kempen et al., 2012) (Deng et al., 2018) (Yang et al., 2017). 
Therefore, parts fabricated by SLM show mechanical properties different from those of conventional parts (Trosch et al., 2016) (Amato et al., 2012) (Kobryn and Semiatin, 2001). The formation of the internal defects in SLM parts can be attributed to porosity, lack of fusion, and cracks. Porosity is induced by the trapping of atmospheric gas at high cooling rates (Thijs et al., 2010) (Bayat et al., 2019) (Gajera et al., 2019). Lack of fusion occurs when the input energy is insufficient to create a molten pool large enough to melt the entire powder layer (Vilaro et al., 2011) (An1 et al., 2018). The generation of cracks is attributed to the residual stress caused by steep temperature gradients (Gu et al., 2012) (Kaufmann et al., 2016) (Harrison et al., 2015) (Han et al., 2018). Owing to these internal defects, SLM parts exhibit mechanical properties inferior to those of forged parts (Zhang et al., 2017) (Balachandramurthi et al., 2018) (Konečná et al., 2016) (Nasab et al., 2019) (Voisin et al., 2018). Internal defects cause stress concentration (Talemi, 2020) and deteriorate the mechanical properties, especially the fatigue properties, of SLM parts. Fatigue fracture in SLM parts originates from their internal defects. (Rao et al., 2019) (Günther et al., 2017) (Beevers et al., 2018) Therefore, as the mechanical properties of SLM parts are significantly affected by the internal defects present in them, computed tomography (CT) has been used to detect the presence of the defects in SLM parts (Snell et al., 2020) (Sangid et al., 2020) (Wits et al., 2016) (Kasperovich et al., 2016). However, from the viewpoint of strength design, it is necessary to determine the internal defect size and investigate its effect on the fatigue characteristics of SLM parts before production.

The effects of the internal defect size on the mechanical properties of aluminum and titanium alloys have been investigated (Romano et al., 2018) (Wycisk et al., 2014) (Masuo et al., 2018) (Biswal et al., 2019) (Beretta and Romano, 2016). However, for Inconel 718, the relationship between the internal defect size and fatigue limit is still unclear. In this study, we carried out fatigue tests on Inconel 718 specimens with internal defects of various sizes. The potential of the $\sqrt{\text { area }}$ parameter model for estimating the internal defect size-dependent fatigue limit of Inconel 718 was evaluated.

\section{Materials and methods}

\subsection{Specimen preparation}

Gas atomized Inconel 718 powder (3D Systems, USA) was used. The chemical composition of Inconel 718 powder is listed in Table 1. Figure 1 shows the scanning electron microscopy (SEM) image of the powder particles. The particle diameter distribution of the powder is shown in Fig. 2, and the average particle diameter of the powder was $35.3 \mu \mathrm{m}$.

Inconel 718 specimens with the dimensions of $15 \times 15 \times 105 \mathrm{~mm}$ were fabricated using an SLM machine (ProX DMP 320, 3D Systems, USA). The SLM processing conditions are listed in Table 2. In order to investigate the effect of the internal defect size on the fatigue properties of Inconel 718, three specimens with different internal defect sizes were fabricated. The introduced defect diameters used in this study were 0,100 , and $400 \mu \mathrm{m}$ and the corresponding specimens were labeled as plane, defect S, and defect L specimens, respectively. Table 3 and Fig. 3 show the CAD data dimensions of the defects introduced into each specimen. In Table $3, \phi$ is the diameter of the defect, $\sqrt{a r e a}$ is the square root of the cross-sectional area of the defect, and $t$ is the length of the defect.

All the specimens were solution treated at $1065{ }^{\circ} \mathrm{C}$ for $1.5 \mathrm{~h}$ followed by dual-temperature precipitation ageing at $720^{\circ} \mathrm{C}$ for $4 \mathrm{~h}$ and at $620^{\circ} \mathrm{C}$ for $4 \mathrm{~h}$.

\subsection{Hardness and fatigue test}

Hardness tests were carried out using a microhardness tester (HMV microhardness tester, Shimadzu, Japan). The tests were carried out using polished samples on a cross-section perpendicular to the build direction. The Vickers hardness of the specimens was measured by applying a load of $0.98 \mathrm{~N}$ for $10 \mathrm{~s}$. For each specimen, 50 indents were performed.

The specimens were machined prior to fatigue testing. The geometry of the specimens is shown in Fig. 4. Fatigue testing was carried out according to ASTM E466 standard using a fatigue tester (Model 1318.10, MTS, USA). Fatigue tests were run under force-controlled constant amplitude conditions at room temperature. All the tests were run at a

Table 1 Chemical composition of Inconel 718.

\begin{tabular}{cccccccc}
\hline Element & $\mathrm{Ni}$ & $\mathrm{Cr}$ & $\mathrm{Fe}$ & $\mathrm{C}$ & $\mathrm{Mn}$ & $\mathrm{Si}$ & $\mathrm{Cu}$ \\
$\mathrm{Wt}[\%]$ & $50.00-55.00$ & $17.00-21.00$ & $\mathrm{Bal}$ & $\leq 0.08$ & $\leq 0.35$ & $\leq 0.35$ & $\leq 0.30$ \\
\hline Element & $\mathrm{Mo}$ & $\mathrm{Co}$ & $\mathrm{Nb}+\mathrm{Ta}$ & $\mathrm{Al}$ & $\mathrm{Ti}$ & $\mathrm{B}$ & \\
$\mathrm{Wt}[\%]$ & $2.80-3.30$ & $\leq 1.00$ & $4.75-5.50$ & $0.2-0.8$ & $0.65-1.15$ & $\leq 0.006$ & \\
\hline
\end{tabular}


stress ratio $(R)$ of 0.1 at a frequency of $25 \mathrm{~Hz}$. The maximum number of cycles was $10^{7}$. The risk volume of the fatigue test specimens, to which maximum stress and minimum stress were loaded, was $339 \mathrm{~mm}^{3}$. After the fatigue testing, fracture surfaces were cut from the fatigue specimens and were then examined using a scanning electron microscope (SEM, Miniscope TM3030Plus, Hitachi, Japan).

\subsection{Defect analysis}

The densities of the heat-treated specimens were measured using the Archimedes principle. The relative densities of the specimens were calculated by dividing their densities by $8.22 \mathrm{~g} / \mathrm{cm}^{3}$. To measure the size of the introduced defects, the defect $\mathrm{S}$ and defect $\mathrm{L}$ specimens were cut perpendicular to the building direction. To estimate the maximum internal defect size of the plane specimen, its internal defect size distribution after the heat treatment was measured. The specimens were cut in the plane perpendicular to the building direction. The surfaces of the specimens were ground gradually up to \#4000 SiC papers. The ground specimens were then polished with $3 \mu \mathrm{m}$ and $1 \mu \mathrm{m}$ diamond powders. Seventy images were acquired from each polished sample using an optical microscope (Multizoom AZ 100, Nikon, Japan) to capture seventy fields of view for measuring the maximum internal defect size. The area of the field of view was $2.51 \mathrm{~mm}^{2}$.

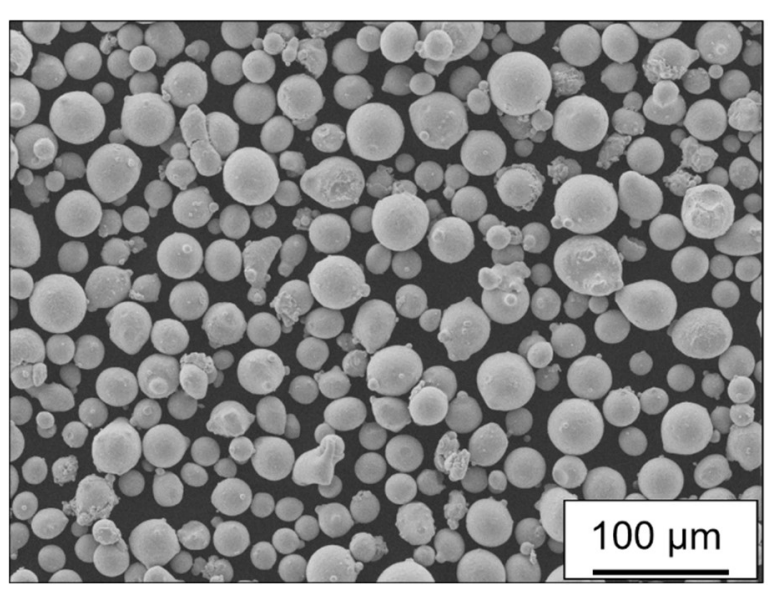

Fig. 1 SEM image of Inconel 718 gas atomized powder.

Table 2 Processing conditions.

\begin{tabular}{ccc}
\hline Laser power & {$[\mathrm{W}]$} & 220 \\
\hline Scan pitch & {$[\mu \mathrm{m}]$} & 100 \\
\hline Scan speed & {$[\mathrm{mm} / \mathrm{s}]$} & 1180 \\
\hline Layer thickness & {$[\mu \mathrm{m}]$} & 30 \\
\hline Laser & & Yb fiber laser $(\mathrm{CW})$ \\
\hline Atmosphere & $\mathrm{Ar}$ \\
\hline
\end{tabular}

Table 3 CAD data dimension of the introduced defects.

\begin{tabular}{cccc}
\hline & $\phi[\mu \mathrm{m}]$ & $\sqrt{\text { area }}[\mu \mathrm{m}]$ & $t[\mu \mathrm{m}]$ \\
\hline plane & 0 & 0 & 0 \\
\hline defect S & 113 & 100 & 2000 \\
\hline defect L & 451 & 400 & 2000 \\
\hline
\end{tabular}

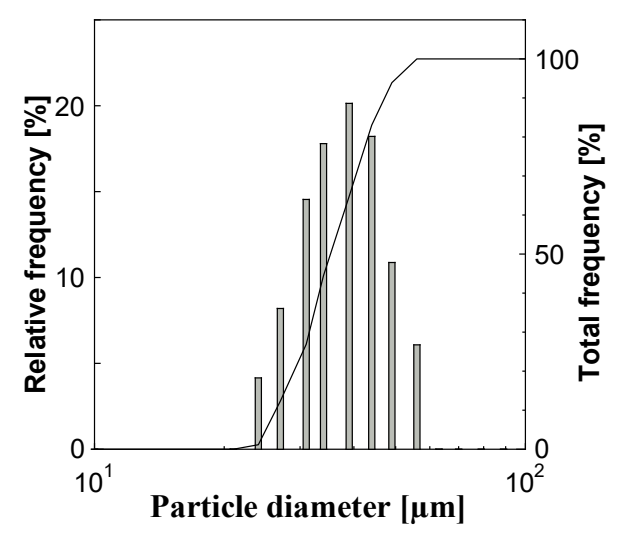

Fig. 2 Particle diameter distribution of Inconel 718 powder.

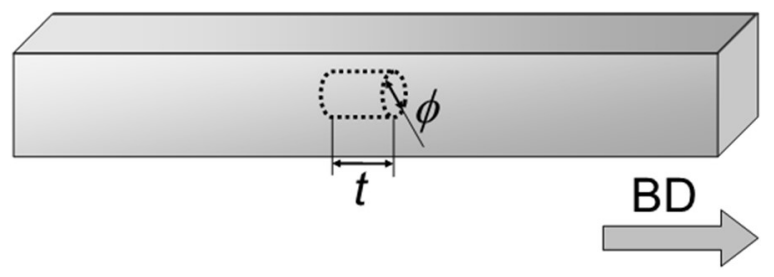

Fig. 3 CAD data dimension of the introduced defect.

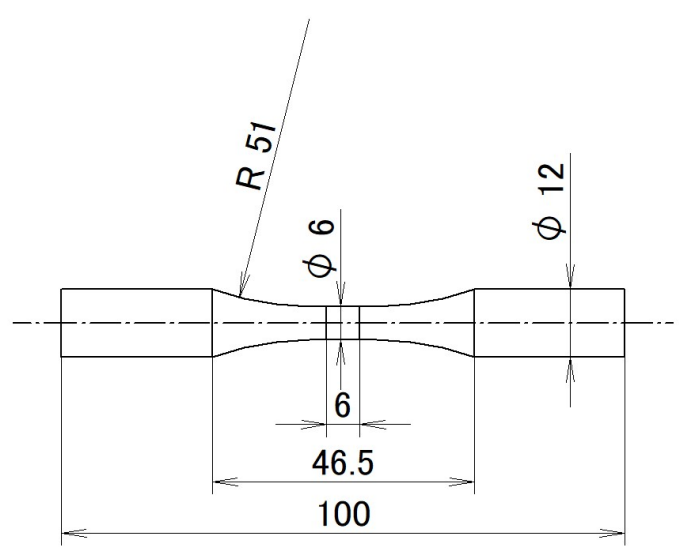

Fig. 4 Shape and dimensions of fatigue specimen. 


\subsection{Fatigue limit prediction}

The maximum inclusion size in an arbitrary volume can be predicted by using the statistic of extremes method (Wycisk, 2014). This method can be applied not only for inclusions, but also for the defects. Gumbel distribution is used as an approximation of the maximum internal defect size distribution in a part. In Eq 1 and 2, $\Phi$ is a cumulative distribution function and $y$ is a standardized variable.

$$
\begin{aligned}
& \Phi(x)=\exp \{-\exp (-y)\} \\
& y=\alpha_{n}\left(x-u_{n}\right)
\end{aligned}
$$

The maximum internal defect size in the risk volume of each specimen could be predicted by extrapolating their Gumbel distribution curves (Gumbel, 2004).

To predict the fatigue limit of alloy parts considering the relationship between the fatigue limit and the size of the largest internal defect, Murakami proposed the $\sqrt{\text { area }}$ parameter model (Murakami, 2014). In this model, the specimen is first cut and the internal defect size is measured. The fatigue limit is then determined from its Vickers hardness and the internal defect size according to Eq. 3.

$$
\sigma_{w}=1.56(\mathrm{HV}+120) \times(\sqrt{\text { area }})^{-1 / 6} \times[(1-R) / 2]^{0.22+\mathrm{HV} \times 10^{-4}}
$$

Here, HV denotes the Vickers hardness of the specimen and $\sqrt{\text { area }}$ is the square root of the cross-sectional area of the defect $(\mu \mathrm{m})$.

The $\sqrt{\text { area }}$ parameter model was devised for fatigue of steel materials. For Inconel materials, it has been reported that the fatigue limit is affected by the crack propagation limit (Kawagoishi et al., 1997). Figure 5 shows the results of investigating the relationship between hardness and tensile strength (Johannes et al., 2015) (Logsdon et al., 1978) (Popovich, et al., 2017) (Schirra , 1997) (Szustecki et al., 2017) and between tensile strength and fatigue limit (David et al., 2020) (Wan et al., 2018) (Zhong et al., 2019) based on the published strength of Inconel materials. There is a linear relationship between hardness and tensile strength, and that there is a linear relationship between tensile strength and fatigue limit. Based on the above, we considered that the material system has the same fatigue properties as steel, and consulted the application of the $\sqrt{\text { area }}$ parameter model for estimating the internal defect size-dependent fatigue limit of Inconel 718.

\section{Results and discussion}

Figure 6 shows the cross-sectional optical microscopy images of the defect S and defect L specimens. These specimens showed uneven surfaces resulting from the partially melted particles adhering to the inner walls of the
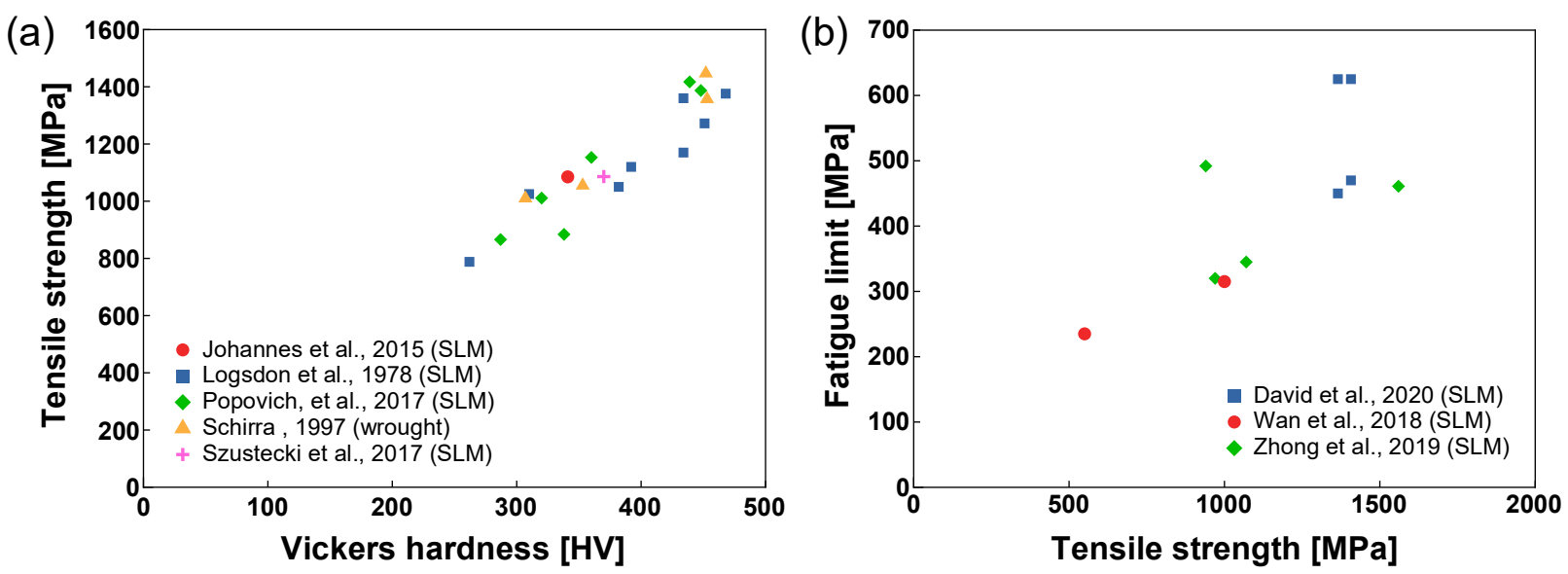

Fig. 5 A linear relationship between hardness and tensile strength (a), and a linear relationship between tensile strength and fatigue limit (b). 
introduced defects. The defect S specimen showed the spherical and irregular defects. The defect L specimen showed the spherical defects (excluding the partially melted particles). As the adhered particles did not bear the load, they were considered as the defects.

Figures 7 show the introduced defect size distributions of the defect $\mathrm{S}$ and the defect $\mathrm{L}$ specimens. No significant change was observed in the introduced defect size of the specimens after the heat treatment. The reproducibility of the defect S specimen was low. Therefore, its $\sqrt{\text { area }}$ variation was larger than that of the defect L specimen. The maximum introduced defect size of the defect $\mathrm{S}$ specimen was $\sqrt{\text { area }}=93.0 \mu \mathrm{m}$, whereas that of the defect $\mathrm{L}$ specimen was $\sqrt{\text { area }}=416 \mu \mathrm{m}$.

The average relative density of 3 specimens, as calculated using the Archimedes principle was 100.2\%. Figure 8 shows the cross-sectional optical microscopy image of the plane specimen. Even though the relative density of the specimen was high, the many internal defects with the diameters of several tens of $\mu \mathrm{m}$ were observed. The internal defects present in the specimens were of two types: spherical (induced by the porosity) and irregular (induced by the lack of fusion).

Figure 9 shows the distribution of the maximum internal defect size occurring in a unit area of the plane logarithm of the cumulative distribution function $F$. The maximum internal defect size observed in 70 field of view was $\sqrt{a r e a}=$ $32.5 \mu \mathrm{m}$. As the difference between the experimental and Gumbel distribution results was very small over the entire measurement area and the coefficient of determination was 0.979 , it can be stated that the maximum internal defect size values of the specimens followed the Gumbel distribution. When extrapolated using this distribution, the maximum internal defect size in the hazardous volume of the fatigue specimen $(\sqrt{\text { area }})$ was estimated to be $62.6 \mu \mathrm{m}$. The average Vickers hardness of the heat-treated specimens was 409 Hv0.1. By substituting the predicted $\sqrt{\text { area }}$ and the Vickers

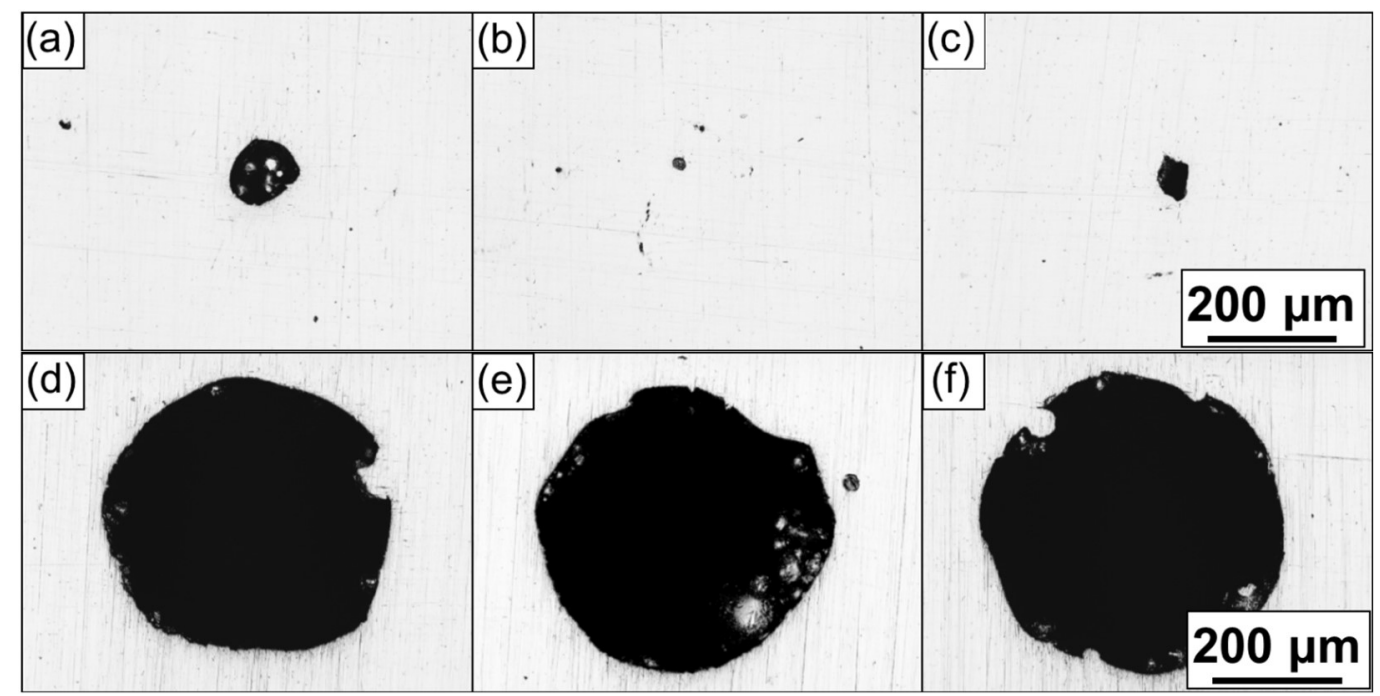

Fig. 6 Cross-sectional OM images of (a)(b)(c) defect S specimen with $100 \mu \mathrm{m}$ internal defect, (d)(e)(f) defect L specimen with $400 \mu \mathrm{m}$ internal defect.

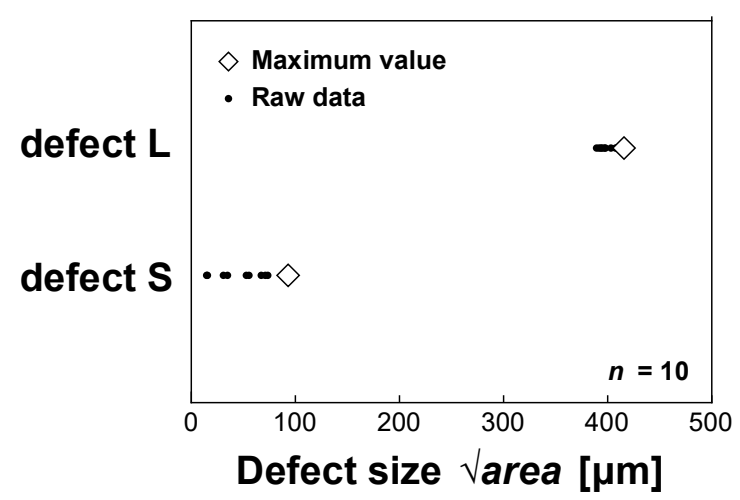

Fig. 7 Introduced defect size distributions of defect S and defect L. 
hardness in Eq 3, the fatigue limit of the plane specimen was estimated to be $335 \mathrm{MPa}$. Similarly, the fatigue limits of the defect $\mathrm{S}$ and defect $\mathrm{L}$ specimens were estimated to be 310 and $246 \mathrm{MPa}$, respectively.

Figure 10 shows the fatigue properties of each specimen. The fatigue limits of the plane, defect $\mathrm{S}$, and defect $\mathrm{L}$ specimens were 239, 245, and $248 \mathrm{MPa}$, respectively. Hence, the specimens showed comparable fatigue limits. At the same stress amplitude, the specimens showed comparable fatigue life values. Although the introduced defects and internal defect size affected the fracture morphology of the specimens, the effect on the fatigue limit was negligible.

Figure 11 shows the SEM images of the fracture surfaces of the specimens. The plane and defect S specimens showed similar fracture morphologies. The fracture surfaces of plane and defect S specimens showed smooth regions. In the smooth regions, cracks propagated from the existing internal defects to the opposite side of the specimen surface. The fracture surfaces of plane and defect $\mathrm{S}$ specimens showed smooth regions. In the smooth regions, cracks propagated from the existing internal defects to the opposite side of the specimen surface. Nishitani and Murakami (1974) showed that when internal defects are formed near the surface, the stress intensity factor of the internal cracks increases. Therefore, the internal defects close to the surface act as crack initiation points. The fracture morphology of the defect L specimen was different from those of the plane and defect S specimens. At low stress amplitudes, only the fracture surface of the defect L specimen showed the internal defects. The fracture morphology of the defect L specimen varied with the stress amplitude. At low stress amplitudes, cracks propagate from the introduced defects. On the other hand, at high stress amplitudes, cracks propagate from the subsurface defects. Sakurai et al. (2017) also observed this change in the crack initiation point of SLM alloys with the stress amplitude. The fracture morphology of the defect L specimen varied because the introduction of the large internal defects caused stress concentration.

The measured and predicted fatigue limits of the specimens are listed in Table 4. The predicted fatigue limits of the specimens were lower than their experimental fatigue limits. The predicted fatigue limit (335 MPa) of the plane specimen (using the $\sqrt{\text { area }}$ parameter model) was $40.2 \%$ higher than its experimental value (239 MPa). The defect L specimen showed a relative error of $0.94 \%$. Thus, the prediction was sufficiently accurate in the case of the defect $\mathrm{L}$ specimen. During the fabrication of SLM parts under optimum conditions, the possibility of the formation of the internal defects with diameters as large as $400 \mu \mathrm{m}$ is very low. Therefore, the use of the $\sqrt{\text { area }}$ parameter model for the prediction of the fatigue limit leads to large errors and overestimation.

\section{Conclusions}

In this study, three Inconel 718 specimens with different internal defect diameters were fabricated by SLM. The effect of the internal defect size on the fatigue properties of the specimens was investigated. The following conclusions were drawn:

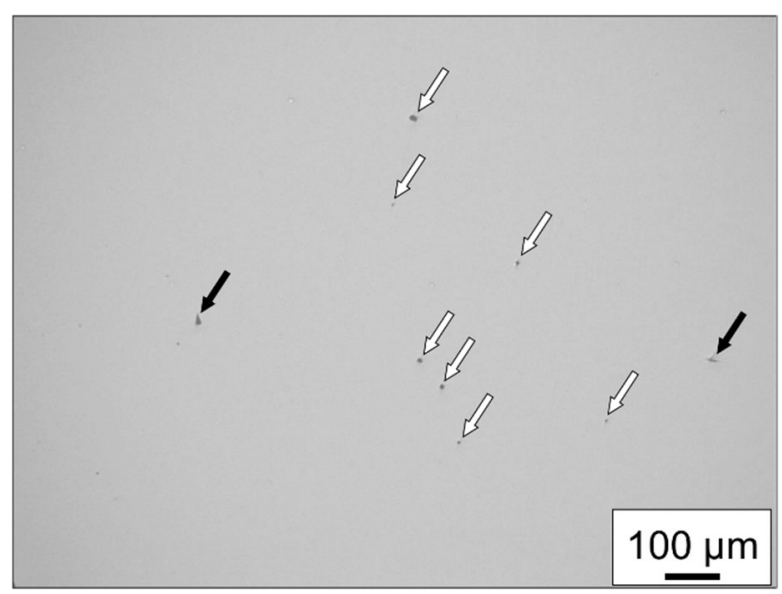

Fig. 8 Cross-sectional optical microscopic images of heat treated plane specimen. (White arrows are spherical pores, black arrows are unmelted regions)

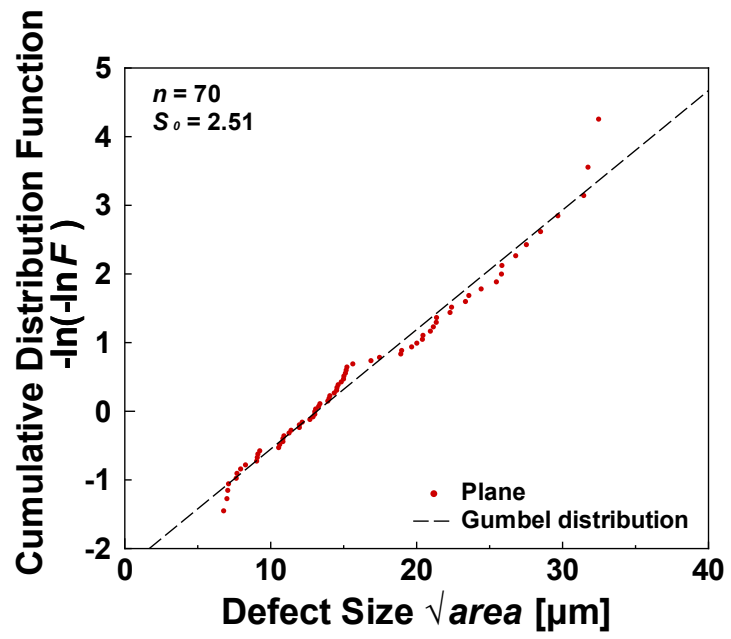

Fig. 9 Defect size distribution of plane specimen and approximation by using Gumbel distribution. 
1. The plane specimen showed internal defects generated by porosity and lack of fusion. The size distribution of the internal defects in this specimen could be approximated by the Gumbel distribution, which is one of the extreme value distributions. When extrapolated using this distribution, the maximum internal defect size in the risk volume of the fatigue specimen was estimated to be $\sqrt{\text { area }}=62.6 \mu \mathrm{m}$.

2. The fatigue limits of the plane, defect $\mathrm{S}$, defect L specimens were 239, 246, and $248 \mathrm{MPa}$, respectively. The fatigue limits of the three specimens were comparable. At the same stress amplitude, the specimens showed comparable fatigue life values. The internal defect size showed negligible effect on the fatigue limit and fatigue life of the defect $\mathrm{S}$ and defect L specimens.

3. In the case of the plane specimen, the fatigue limit predicted using the $\sqrt{\text { area }}$ parameter model was $40 \%$ higher than that obtained experimentally. This error can be attributed to the failure mechanism of Inconel 718 fabricated by SLM. In the future, we will investigate this mechanism.

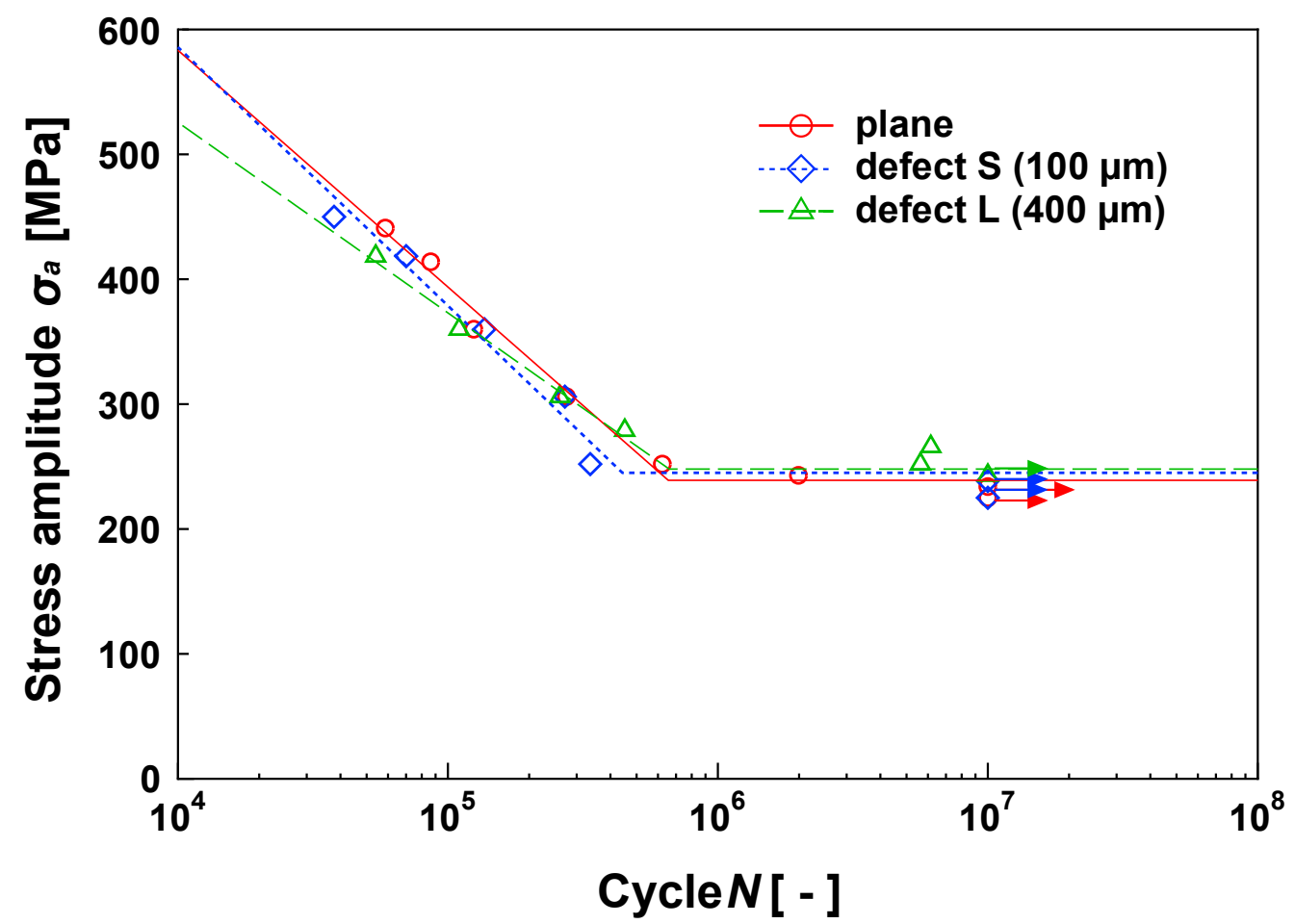

Fig. 10 Fatigue properties of the three specimens.

Table 4 Tested and predicted fatigue strength.

\begin{tabular}{cccc}
\hline & \multicolumn{2}{c}{ Fatigue strength [MPa] } & \multirow{2}{*}{$\begin{array}{c}\text { Relative Error } \\
{[\%]}\end{array}$} \\
\cline { 2 - 3 } & Experimental & Predicted & 40 \\
\hline plane & 239 & 335 & 26 \\
\hline defect S & 246 & 310 & 0.94 \\
\hline defect L & 248 & 246 & \\
\hline
\end{tabular}




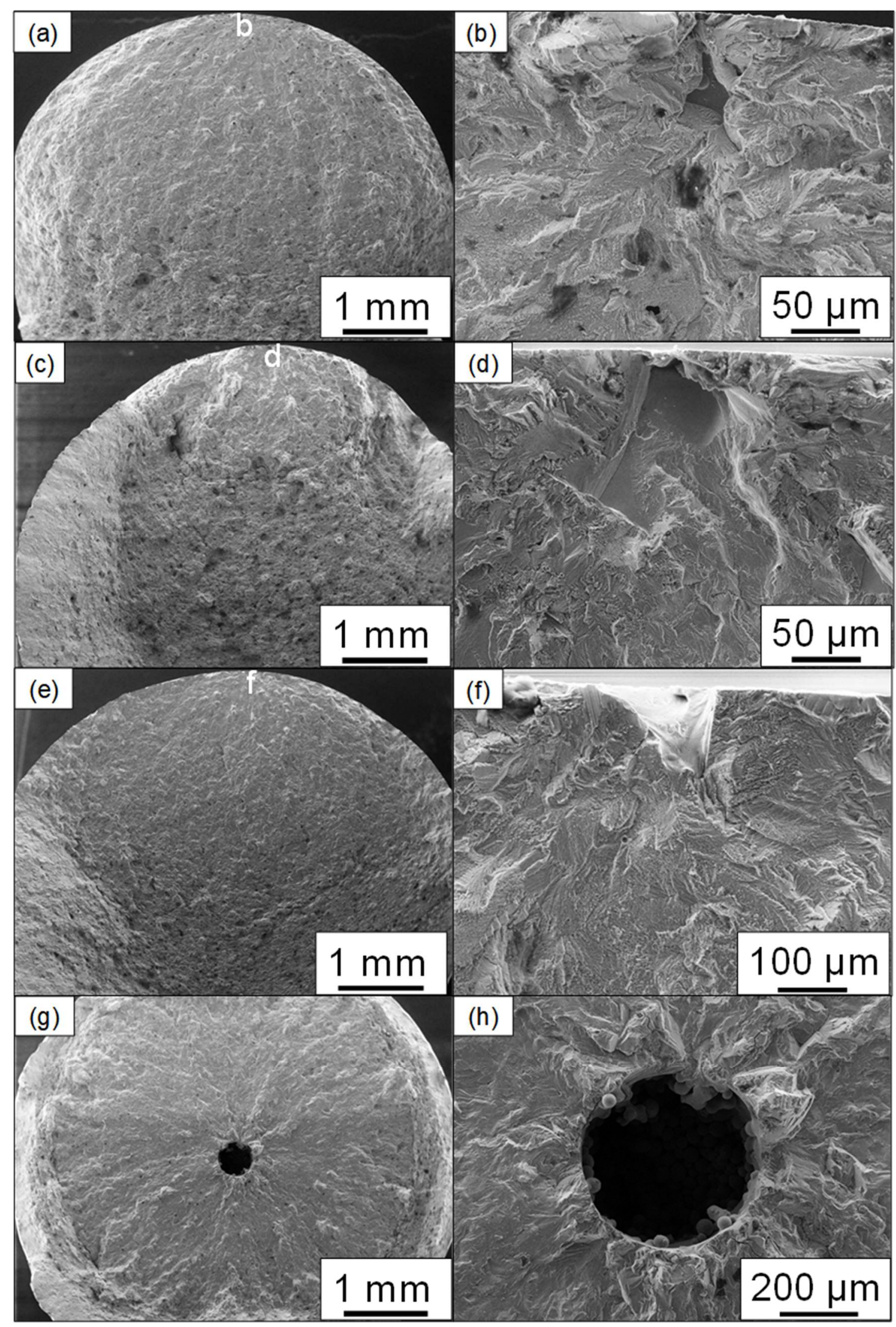

Fig. 11 Fractographs obtained from the crack initiation locations. (a), (b) plane $\left(\sigma_{a}=243 \mathrm{MPa}, N_{f}=1988593\right),(\mathrm{c}),(\mathrm{d})$ defect S ( $\left.\sigma_{a}=252 \mathrm{MPa}, N_{f}=336692\right)$, (e), (f), defect L ( $\left.\sigma_{a}=306 \mathrm{MPa}, N_{f}=260052\right),(\mathrm{g}),(\mathrm{h}) \operatorname{defect} \mathrm{L}\left(\sigma_{a}=266\right.$ $\left.\mathrm{MPa}, N_{f}=6151719\right)$ 


\section{References}

Akca, E. and Gursel, A., A Review on Superalloys and IN718 Nickel-Based INCONEL Superalloy, Periodicals of Engineering and Natural Science, Vol.3, No.1 (2015), pp.15-27, DOI:10.21533/pen.v3i1.43.

Amato, K. N., Gaytan, S. M., Murr, L. E., Martinez, E., Shindo, P. W., Hernandez, J., Collins, S. and Medina, F., Microstructures and mechanical behavior of Inconel 718 fabricated by selective laser melting, Acta Materialia, Vol.60, No.5 (2012), pp.2229-2239, DOI:10.1016/j.actamat.2011.12.032.

An1, C., Zhang, J. S., Zhang, Y. M., Lv, D. X. and Ruan, L, Experimental Study on Density and Pore Defect of Cobalt-chromium Alloy Manufactured by Selective Laser Melting, IOP Conference Series: Materials Science and Engineering, Vol.382 (2018), DOI:10.1088/1757-899X/382/2/022082.

Arunachalam, R.M., Mannan, M.A. and Spowage, A.C., Surface integrity when machining age hardened Inconel 718 with coated carbide cutting tools, International Journal of Machine Tools and Manufacture, Vol.44, No.14 (2004), pp.1481-1491, DOI:10.1016/j.ijmachtools.2004.05.005.

Balachandramurthi, A. R., Moverare, J., Dixit, N. and Pederson, R., Influence of defects and as-built surface roughness on fatigue properties of additively manufactured Alloy 718, Materials Science and Engineering: A, Vol.735 (2018), pp.463-474, DOI:10.1016/j.msea.2018.08.072.

Bayat, M., Thanki, A., Mohanty, S., Witvrouw, A., Yang, S., Thorborg, J., Tiedje, N. S. and Hattel, J. H., Keyhole-induced porosity in Laser-based Powder Bed Fusion (L-PBF) of Ti6Al4V: High-fidelity modelling and experimental validation, Additive Manufacturing, Vol.30 (2019), DOI:10.1016/j.addma.2019.100835.

Beevers, E., Brandão, A. D., Gumpinger, J., Gschweitl, M., Seyfert, C., Hofbauer, P., Rohr, T. and Ghidini, T., Fatigue properties and material characteristics of additively manufactured AlSi10Mg - Effect of the contour parameter on the microstructure, density, residual stress, roughness and mechanical properties, International Journal of Fatigue, Vol.117 (2018), pp.148-162, DOI:10.1016/j.ijfatigue.2018.08.023.

Beretta, S. and Romano, S., A comparison of fatigue strength sensitivity to defects for materials manufactured by AM or traditional processes, International Journal of Fatigue, Vol.94, No.2 (2017), pp.178-191, DOI:10.1016/j.ijfatigue.2016.06.020.

Biswal, R., Zhang, X., Syed, A. K., Awd, M., Ding, J., Walther, F. and Williams, S., Criticality of porosity defects on the fatigue performance of wire+arc additive manufactured titanium alloy, International Journal of Fatigue, Vol.122 (2019), pp.208-217, DOI:10.1016/j.ijfatigue.2019.01.017.

David, B., Witkin, Dhruv P., Thomas, V., Albright, Glenn E., Bean, Tait M., Influence of surface conditions and specimen orientation on high cycle fatigue properties of Inconel 718 prepared by laser powder bed fusion, International Journal of Fatigue, Vol.132 (2020), 105392, DOI:10.1016/j.ijfatigue.2019.105392.

Deng, D., Peng, R. L., Brodin, H. and Moverare, J., Microstructure and mechanical properties of Inconel 718 produced by selective laser melting: Sample orientation dependence and effects of post heat treatments, Materials Science and Engineering: A, Vol.713 (2018), pp.294-306, DOI:10.1016/j.msea.2017.12.043.

Gajera, H. M., Dave, K. G., Darji, V. P. and Abhishek, K., Optimization of process parameters of direct metal laser sintering process using fuzzy-based desirability function approach, Journal of the Brazilian Society of Mechanical Sciences and Engineering, Vol.41, No.124 (2019), DOI:10.1007/s40430-019-1621-2.

Gu, D., Hagedorn, Y. C., Meiners, W., Meng, G., Batista, R. J. S., Wissenbach, K. and Poprawe, R., Densification behavior, microstructure evolution, and wear performance of selective laser melting processed commercially pure titanium, Acta Materialia, Vol.60, No.9 (2012), pp.3849-3860, DOI:10.1016/j.actamat.2012.04.006.

Gumbel, E. J., Statistics of Extremes (2004), pp.156-157, Dover Publications INC.

Günther, J., Krewerth, D., Lippmann, T., Leuders, S., Tröster, T., Weidner, A., Biermann, H. and Niendorf, T., Fatigue life of additively manufactured Ti-6Al-4V in the very high cycle fatigue regime, International Journal of Fatigue, Vol.94, No.2 (2017), pp.236-245, DOI:10.1016/j.ijfatigue.2016.05.018.

Han, Q., Mertens, R., Montero-Sistiaga, M. L., Yang, S., Setchi, R., Vanmeensel, K., Hooreweder, B. V., Evans, S. L. and Fan, H., Laser powder bed fusion of Hastelloy X: Effects of hot isostatic pressing and the hot cracking mechanism, Materials Science and Engineering: A, Vol.732 (2018), pp.228-239, DOI:10.1016/j.msea.2018.07.008.

Harrison, N. J., Todd, I. and Mumtaz, K., Reduction of micro-cracking in nickel superalloys processed by Selective Laser Melting: A fundamental alloy design approach, Acta Materialia, Vol.94 (2015), pp.59-68, 
DOI:10.1016/j.actamat.2015.04.035.

Johannes, S., Michael, T., Uwe, G., Mechanical and Microstructural Investigation of Nickel - Based Superalloy IN718 Manufactured by Selective Laser Melting (SLM), Advanced Engineering Materials, Vol.17, No.8 (2015), pp.1099-1105, DOI:10.1002/adem.201500158.

Kasperovich, G., Haubrich, J., Gussone, J. and Requena, G., Correlation between porosity and processing parameters in TiAl6V4 produced by selective laser melting, Materials \& Design, Vol.105 (2016), pp.160-170, DOI:10.1016/j.matdes.2016.05.070.

Kaufmann, N., Imran, M., Wischeropp, T.M., Emmelmann, C., Siddique, S. and Walther, F., Influence of Process Parameters on the Quality of Aluminium Alloy EN AW 7075 Using Selective Laser Melting (SLM), Physics Procedia, Vol.83 (2016), pp.918-926, DOI:10.1016/j.phpro.2016.08.096.

Kawagoishi, N., Chen, Q., Tanaka, H., Maeno, Ichiro., Kiyofuji, Jun-ichi., Characteristics of Small Crack Growth in a Nickel-Base Superalloy, Transaction of the Japan Society of Mechanical Engineers A, Vol.63, No.611 (1997), pp.1398-1402 (in Japanese).

Kempen, K., Thijs, L., Humbeeck, J. V. and Kruth, J. P., Mechanical Properties of AlSi10Mg Produced by Selective Laser Melting, Physics Procedia, Vol.39 (2012), pp.439-446, DOI:10.1016/j.phpro.2012.10.059.

Kobryn, P.A. and Semiatin, S.L., Mechanical Properties of Laser-Deposited Ti-6Al-4V 179, International Solid Freeform Fabrication Symposium (2001), DOI:10.26153/tsw/3261.

Konečná, R., Kunz, L., Nicoletto, G. and Bačaa, A., Long fatigue crack growth in Inconel 718 produced by selective laser melting, International Journal of Fatigue, Vol.92, No.2 (2016), pp.499-506, DOI:10.1016/j.ijfatigue.2016.03.012.

Logsdon, W. A., Kossowsky, R., Wells, J. M., The Influence of Processing and Heat Treatment on the Cryogenic Fracture Mechanics Properties of Inconel 718, Advances in Cryogenic Engineering, Vol.24 (1978), pp.197-209.

Masuo, H., Tanaka, Y., Morokoshi, S., Yagura, H., Uchida, T., Yamamoto, Y. and Murakami, Y., Influence of defects, surface roughness and HIP on the fatigue strength of Ti-6Al-4V manufactured by additive manufacturing, International Journal of Fatigue, Vol.117 (2018), pp.163-179, DOI:10.1016/j.ijfatigue.2018.07.020.

Murakami, Y., Metal Fatigue: Effects of Small Defects and Nonmetallic Inclusions (2014), p.58, Elsevier Science.

Nasab, M. H., Giussani, A., Gastaldi, D., Tirelli, V. and Vedani, M., Effect of Surface and Subsurface Defects on Fatigue Behavior of AlSi10Mg Alloy Processed by Laser Powder Bed Fusion (L-PBF), Metals, Vol.9, No.10 (2019), DOI:10.3390/met9101063.

Nishitani, H. and Murakami, Y., Stress Intensity Factors of Semi-Elliptical Crack and Elliptical Crack: Tension, International Journal of Fracture, Vol.10 (1974), pp.31-40, DOI:10.1007/BF00035496.

Popovich, V. A., Borisov, E. V., Popovich, A.A., Sufiiarov, V.Sh., Masaylo, D.V., Alzina, L., Impact of heat treatment on mechanical behaviour of Inconel 718 processed with tailored microstructure by selective laser melting, Materials \& Design, Vol.131 (2017), pp.12-22, DOI:10.1016/j.matdes.2017.05.065.

Rao, J. H., Zhang, Y., Huang, A., Wu, X. and Zhang, K., Improving fatigue performances of selective laser melted Al-7Si-0.6Mg alloy via defects control, International Journal of Fatigue, Vol.129 (2019), DOI:10.1016/j.ijfatigue.2019.105215.

Romano, S., Brückner-Foit, A., Brandão, A., Gumpinger, J., Ghidini, T. and Beretta, S., Fatigue properties of AlSi10Mg obtained by additive manufacturing: Defect-based modelling and prediction of fatigue strength, Engineering Fracture Mechanics, Vol.187 (2018), pp.165-189, DOI:10.1016/j.engfracmech.2017.11.002.

Sakurai, K., Miyai, Y., Hasunuma, S., Ogawa, T., Woo, M. and Takanashi, M., Fatigue Crack Growth Threshold of Ni Based Castalloys Using Ultrasonic Fatigue Tests, Journal of the Society of Material Science (in Japanese), Vol.66 (2017), pp.970-886, DOI:10.2472/jsms.66.879.

Sangid, M. D., Ravi, P., Prithivirajan, V., Miller, N. A., Kenesei, P. and Park, J. S., ICME Approach to Determining Critical Pore Size of IN718 Produced by Selective Laser Melting, The Journal of The Minerals, Vol.72 (2020), pp.465-474, DOI:10.1007/s11837-019-03910-0.

Schirra, John J., Effect of Heat Treatment Variations on the Hardness and Mechanical Properties of Wrought InconeI 718, Superalloy, (1997), pp.431-438.

Sharman, A., Dewes, R. C. and Aspinwall, D. K., Tool life when high speed ball nose end milling Inconel $718^{\mathrm{TM}}$, Journal of Materials Processing Technology, Vol.118, No.1-3 (2001), pp.29-35, DOI:10.1016/S0924-0136(01)00855-X. 
Snell, R., Williams, S. T., Chechik, L., Lyle, A., Nava, E. H., Boig, C., Panoutsos, G. and Todd, I., Methods for Rapid Pore Classification in Metal Additive Manufacturing. The Journal of The Minerals, Vol.72 (2020), pp.101-109, DOI:10.1007/s11837-019-03761-9.

Sridharan, N., Gussev, M., Seibert, R., Parish, C., Norfolk, M., Terrani, K. and Babu, S. S., Rationalization of anisotropic mechanical properties of Al-6061 fabricated using ultrasonic additive manufacturing, Acta Materialia, No.117 (2016), pp.228-237, DOI:10.1016/j.actamat.2016.06.048.

Szustecki, M., Zrodowski, L., Sitek, R., Cygan, R., Pakiela, Z., Moronczyk, B., Mizera, J. Microstructure and properties of in 718 nickel-based superalloy manufactured by means of selective laser melting method, Advanced Applied Plasma Science, Vol.11 (2017), pp.9-12.

Talemi, R., A numerical study on effects of randomly distributed subsurface hydrogen pores on fretting fatigue behaviour of aluminium AlSi10Mg, Tribology International, Vol.142 (2020), DOI:10.1016/j.triboint.2019.105997.

Thijs, L., Verhaeghe, F., Craeghs, T., Humbeeck, J. V. and Kruth, J. P., A study of the microstructural evolution during selective laser melting of Ti-6Al-4V, Acta Materialia, Vol.58, No.9 (2010), pp.3303-3312, DOI:10.1016/j.actamat.2010.02.004.

Trosch, T., Strößner, J., Völkl, R. and Glatzel, U., Microstructure and mechanical properties of selective laser melted Inconel 718 compared to forging and casting, Materials Letters, Vol.164 (2016), pp.428-431, DOI:10.1016/j.matlet.2015.10.136.

Vilaro, T., Colin, C. and Bartout, J., As-Fabricated and Heat-Treated Microstructures of the Ti-6Al-4V Alloy Processed by Selective Laser Melting, Metallurgical and Materials Transactions A, Vol.42 (2011), pp.3190-3199, DOI:10.1007/s11661-011-0731-y.

Voisin, T., Calta, N. P., Khairallah, S. A., Forien, J. B., Balogh, L., Cunningham, R. W., Rollett, A. D. and Wang, Y. M., Defects-dictated tensile properties of selective laser melted Ti-6Al-4V, Materials \& Design, Vol.158 (2018), pp.113-126, DOI:10.1016/j.matdes.2018.08.004.

Wan, H. Y., Zhou, Z. J., Li, C. P., Chen, G. F., Zhang, G. P., Enhancing Fatigue Strength of Selective Laser Melting Fabricated Inconel 718 by Tailoring Heat Treatment Route, Advanced Engineering Materials, Vol.20 (2018), DOI:10.1002/adem.201800307.

Wits, W. W., Carmignato, S., Zanini, F. and Vaneker, T. H. J., Porosity testing methods for the quality assessment of selective laser melted parts, CIRP Annals, Vol.65, No.1 (2016), pp.201-204, DOI:10.1016/j.cirp.2016.04.054.

Wycisk, E., Solbach, A., Siddique, S., Herzog, D., Walther, F. and Emmelmann, C., Effects of Defects in Laser Additive Manufactured Ti-6Al-4V on Fatigue Properties, Physics Procedia, Vol.56 (2014), pp.371-378, DOI:10.1016/j.phpro.2014.08.120.

Yang, J., Yu, H., Wang, Z. and Zeng, X., Effect of crystallographic orientation on mechanical anisotropy of selective laser melted Ti-6Al-4V alloy, Materials Characterization, Vol.127 (2017), pp.137-145, DOI:10.1016/j.matchar.2017.01.014.

Zhang, B., Li, Y. and Bai, Q., Defect Formation Mechanisms in Selective Laser Melting: A Review, Chinese Journal of Mechanical Engineering, Vol.30 (2017) pp.515-527, DOI:10.1007/s10033-017-0121-5.

Zhang, X., Chen, Y. and Hu, J., Recent advances in the development of aerospace materials, Progress in Aerospace Sciences, Vol.97 (2018), pp.22-34, DOI:10.1016/j.paerosci.2018.01.001.

Zhong, L., Hu, H., Liang, Y., Huang, C. High Cycle Fatigue Performance of Inconel 718 Alloys with Different Strengths at Room Temperature, Metals, Vol.9, No.13 (2019), DOI:10.3390/met9010013. 